\title{
Dopamine depletion in neonatal rats: effects on behavior and striatal dopamine release assessed by intracerebral microdialysis during adulthood
}

\author{
Edward Castañeda $^{1}$, Ian Q. Whishaw ${ }^{1}$, Leonard Lermer ${ }^{1}$ and Terry E. Robinson ${ }^{2}$ \\ ${ }^{\prime}$ Department of Psychology, University of Lethbridge, Lethbridge, Alta. (Canada) and ${ }^{2}$ The University of Michigan, Ann Arbor, MI 48109 \\ (U.S.A.)
}

(Accepted 29 June 1989)

Key words: Recovery and sparing of function; Development; Amphetamine; Dialysis; Dihydroxyphenylacetic acid; Dopamine release; Homovanillic acid; 5-Hydroxyindoleacetic acid; Noradrenaline; 6-Hydroxydopamine in infant rats; Locomotion

\begin{abstract}
Rats depleted of dopamine (DA) by intraventricular 6-hydroxydopamine (6-OHDA) in infancy show behavioral impairments as adults, but their basic sensory-motor functions and feeding abilities are intact; at least relative to the pronounced deficits seen in rats given similar treatment in adulthood. Here we investigate whether presynaptic changes culminating in enhanced DA release are present in adult rats that received neonatal damage, and whether these are of a sufficient magnitude to contribute to the sparing of function. We used microdialysis in rats during the resting state, walking on a treadmill, and after a systemic injection of amphetamine. It was found that neonatal 6-OHDA produced a nearly complete $(<1 \%$ of control) depletion of DA in postmortem tissue, but this was not accompanied by a comparable decline in the basal extracellular concentrations of DA, which were only reduced by $12-54 \%$ of control values. In contrast, the extracellular concentrations of DA metabolites were greatly reduced, reflecting the post-mortem tissue concentrations of DA. Nevertheless, neonatally depleted animals were markedly deficient in their ability to respond to an amphetamine challenge, both behaviorally and in their ability to further increase DA release. Thus, following neonatal DA depletion there appear to be extensive changes in the few remaining DA terminals that are sufficient to maintain relatively high extracellular (and presumably synaptic) concentrations of DA during the resting state, but the capacity of the remaining DA neurons to respond to increased demand is very limited. This presynaptic compensatory response may play a role in the sparing of behavioral function seen following neonatal damage.
\end{abstract}

\section{INTRODUCTION}

The behavior of rats depleted of dopamine (DA) in infancy is very different than the behavior of rats depleted of DA in adulthood. Extensive damage to the neostriatal DA system in adult rats produces a syndrome that is similar to Parkinson's disease in humans ${ }^{25,37}$. The rats display bradykinesia, sensorimotor neglect, aphagia, adipsia, short-step locomotion, akathisia, excessive bracing and clinging reactions and cognitive dysfunction ${ }^{24}$ $34,35,46,50,52,54,58,59$. Extensive damage to the mesostriatal DA system in neonatal rats produces regulatory deficits, and impairments in some aspects of motor behavior, sensory responsiveness, and cognitive function, but other behaviors are much less affected than in rats depleted of DA in adulthood ${ }^{6,8,9,41,53}$. Functions that are relatively spared in neonates include spontaneous locomotor activity, the ability to ingest dry food and water, and to orient to certain forms of sensory stimulation ${ }^{7,12.33}$. In fact, neonatally depleted rats are hyperkinetic ${ }^{12,29}$, which contrasts markedly with the paucity of spontaneous locomotor activity seen in adult depleted rats. This has led some workers to suggest that neonatally depleted rats are more representative of an animal model of minimal brain dysfunction than of adult Parkinsonism ${ }^{29,40}$.

In adult animals DA depletion is accompanied by a number of compensatory neural responses that are thought to contribute to the recovery of function characteristic of DA-depletion syndromes ${ }^{23}$. Presynaptic changes, including an increase in the synthesis, metabolism, and fractional release of DA occur after even moderate damage. For example, using rats with a unilateral DA depletion, Robinson and Whishaw ${ }^{31}$ showed that the extracellular concentrations of DA in the damaged hemisphere were much higher than would be predicted by the extent of the DA depletion measured in post-mortem tissue. It has been suggested that these presynaptic compensatory responses may be largely responsible for the rapid recovery and sparing of function seen after partial lesions in adults $2,4,19,21,31,43,56$. If the depletion of striatal DA exceeds about $80-90 \%$ there is also an increase in the number of postsynaptic DA

Correspondence: E. Castañeda, Department of Psychology, University of Lethbridge, Lethbridge, Alta. T1K $3 \mathrm{M} 4$ Canada. 
receptors (receptor supersensitivity). A combination of pre- and post-synaptic changes is thought to be largely responsible for the recovery of function that occurs subsequent to extensive DA depletion ${ }^{10,14,26,27,49}$.

The neural mechanisms that contribute to the sparing of function seen in rats depleted of DA as neonates have received much less attention. Nevertheless, the earlier report of Robinson and Whishaw ${ }^{31}$ raises the possibility that in neonatally depleted rats the remaining DA terminals may be sufficiently active to produce a functionally adequate supply of extracellular DA, and that this contributes to sparing of function. The purpose of the present study was to determine if this is the case by directly measuring the extracellular concentrations of DA in the striatum, by use of intracerebral microdialysis in adult rats treated with 6-hydroxydopamine (6-OHDA) as neonates. This was done under a variety of behavioral conditions, including the resting state, walking on a treadmill and after a systemic injection of amphetamine. The post-mortem tissue concentrations of DA were also determined to estimate the magnitude of the lesion, and for comparison with the extracellular concentrations of DA measured in vivo.

\section{MATERIALS AND METHODS}

\section{Overview of the protocol}

Rats were given intraventricular 6-OHDA or saline injections on day 3 post-partum. At 27 days of age they were weaned, removed from the sawdust-floored maternity cages, and housed in pairs in wire mesh hanging cages. Thereafter, they were weighed and handled weekly. Formal testing (see below) began when the rats were 6 months of age and included the following: (1) measurement of spontaneous activity in photocell-based activity monitors for 24 $h(13.00-13.00 \mathrm{~h}) ;(2)$ stereotaxic surgery for the implantation of a microdialysis probe, and starting at least $18 \mathrm{~h}$ later dialysate was collected during 3 conditions -- the baseline resting state, during walking on a treadmill and then after an injection of amphetamine; (3) after all of the rats had been tested they were decapitated and post-mortem tissue samples were obtained for subsequent biochemical analysis.

\section{Subjects}

The subjects werc 10 male and 10 female Long-Evans (University of Lethbridge Vivarium) rats obtained from 4 litters culled to 5 rats each. They werc housed on a $14: 10 \mathrm{~h}$ light-dark cycle (lights on $08.00 \mathrm{~h}$ ), and with free access to food and water. Five male and 5 female rats received 6-OHDA as neonates and the remaining 10 animals received control surgery.

\section{Test chambers}

Spontaneous locomotor activity was tested in photocell activity monitors constructed from wire-hanging cages. The individual cages were $40 \mathrm{~cm}$ long. $25 \mathrm{~cm}$ deep and $14 \mathrm{~cm}$ high, with two parallel horizontal infrared beams $1 \mathrm{~cm}$ above the floor, $34 \mathrm{~cm}$ apart, and perpendicular to the long axis of the cage. The total number of crosses between the two photocells, registered incrementally each hour by an Apple II + computer, was used as an index of activity. The computer was programmed in such a way that a rat had to activate each photocell in succession in order to register a count. Therefore, activity counts represent locomotion from one side of the cage to the other ('crossovers').
During the dialysis procedure, rats were placed in a Plexiglas test chamber that was $31 \mathrm{~cm}$ wide $\times 31 \mathrm{~cm}$ deep $\times 35 \mathrm{~cm}$ high. Each chamber had a woodchip-covered floor, and provided access to both food and water. The activity of the animals in the test chamber was monitored via a color camera attached to a Sony SI. 2500 video recorder.

Forced locomotion was achieved by placing the rats in one of two $14 \mathrm{~cm}$ wide $\times 36 \mathrm{~cm}$ long $\times 33 \mathrm{~cm}$ high Plexiglas boxes mounted on a conveyor belt, which was driven at a speed of $300 \mathrm{~cm} / \mathrm{min}$.

\section{Surgical procedures}

Neonatal dopamine depletion. On day 3 post-partum the pups were anesthetized with cold by placing them in a $-5{ }^{\circ} \mathrm{C}$ controlled environment 15 min prior to surgery, and they were then randomly assigned to the treatment or control group. Fifteen min prior to cooling the rats were administered dismethylimipramine $(25 \mathrm{mg} / \mathrm{kg}$, s.c. in the neck), an inhibitor of norepinephrine uptake, which has been shown to reduce the toxic effects of 6-OHDA on noradrenergic nerve terminals 5 . The pups were then placed in a head holder, the skull was exposed, and the pups received either $10 \mu$ of the vehicle solution $(0.9 \%$ sodium chloride and $0.1 \%$ ascorbic acid) or $10 \mu$ of the 6-OHDA solution (vehicle plus $150 \mu \mathrm{g} \mathrm{6-OHDA}$, free base, Sigma). Half of the injection was given in the right lateral ventricle and half of the injection was given in the left lateral ventricle, over $3 \mathrm{~min}$ each (coordinates, anterior to bregmat $0.5 \mathrm{~mm}$. lateral to the midsagittal fissure $1.5 \mathrm{~mm}$ and ventral to the skull surface $2.5 \mathrm{~mm}$; see Whishaw et al. ${ }^{53}$ for details).

Dialysis probe implants. On the day prior to microdialysis the animals were anesthetized with sodium pentobarbital $(30-35 \mathrm{mg} / \mathrm{kg}$, i.p.) and a dialysis probe stereotaxically placed into the corpus of the striatum on either the left or right side, with the side chosen randomly. The dialysis probe (see below) was connected to a $1.0 \mathrm{ml}$ gastight Hamilton 1000 series syringe mounted on a syringe pump (Harvard Apparatus Model 22), and a modified Ringer solution (147 $\mathrm{mmol} \mathrm{Na}^{+}, 2.3 \mathrm{mmol} \mathrm{Ca}^{\dagger}, 4 \mathrm{mmol} \mathrm{K}$ and $155.6 \mathrm{mmol} \mathrm{Cl}$. pH 6.0) pumped through the probe at a rate of $1-2 \mu / / \mathrm{min}$ during the entire surgical procedure. (All solutions were filtered with 0.2 $\mu \mathrm{m}$ syringe filters.) The entire assembly was held in place by enclosing it in dental cement, and it was fixed to the skull with stainless-steel screws. The animals were then placed into the test chamber and left there overnight, with the Ringer solution being pumped through the probes at $0.15 \mu \mathrm{l} / \mathrm{min}$ during this time. Testing began the next day between 08.00 and $10.00 \mathrm{~h}$. at least $18 \mathrm{~h}$ after probe implantation (see below).

\section{Construction of the dialysis probes}

The dialysis probes were similar to those described previously by Robinson and Whishaw ${ }^{3 !}$. The inlet tubing, which was connected to one channel of a 2-channel liquid swivel (Harvard Bioscience), consisted of an approximately 60-cm length of Intramedic PE-20 tubing (Cole-Palmer). The other end of the PE-20 tubing was connected to a section of 26-gauge stainless-steel tubing, which previously had been prepared as follows. An approximately $10 \mathrm{~mm}$ long piece of regenerated cellulose hollow fiber dialysis tubing was cemented into the distal end of the stainless-steel tubing with 2-Ton clear epoxy (Devcon). After the junction was dry to the touch (a few hours) the dialysis fiber was trimmed to $4.25 \mathrm{~mm}$, the tip sealed with epoxy (0.25 mm thick dollop), and then left to dry overnight. The dialysis fiber (Spectra/Por; Spectrum Medical) had a nominal molecular weight cut-off of $50(0)-60(0)$, an i.d. of $215 \mu \mathrm{m}$, and a wall thickness of $18 \mu \mathrm{m}(\mathrm{o} . \mathrm{d} .=233 \mu \mathrm{m})$. The outlet tubing consisted of a $50-\mathrm{cm}$ length of flexible fused silica capillary tubing with an o.d. of $150 \mu \mathrm{m}$ and i.d. of $75 \mu \mathrm{m}$ (Polymicro Technologies). The capillary tubing was incorporated into the probe by slipping it through the 26-gauge stainless-steel cannula and into the dialysis chamber via a small hole pierced through the inlet tubing with a 30 -gauge needle The entire upper portion of the assembly. including the junction between the inlet tubing and stainless steel cannula, and the area where the outlet tubing pierced the inlet tubing, was sealed with a coating of 2-Ton epoxy. After the epoxy had cured probes were 
stored dry, suspended in air and protected from dust.

Measurement of probe recovery in vitro

At least 2 days prior to implantation all probes were flushed thoroughly. The flushing procedure consisted of pumping filtered high-performance liquid chromatography (HPLC) grade water through the probes, initially at $1-2 \mu \mathrm{l} / \mathrm{min}$. For the first $20 \mathrm{~min}$ the dialysis tips were placed in a beaker containing $70 \%$ ethyl alcohol (to remove the isopropyl myristate with which the fibers are originally filled). Next, the tips were placed in HPLC water and the probes left to flush overnight at approximately $0.5 \mu \mathrm{l} / \mathrm{min}$. The next day, the water was removed from the probes by gentle suction with the attached syringe and they were filled with freshly prepared filtered Ringer solution. The Ringer solution was pumped through the probes at $1.5 \mu \mathrm{l} / \mathrm{min}$, with the dialysis tips in a beaker containing Ringer solution. After at least $30 \mathrm{~min}$ the beaker of Ringer was replaced with a beaker containing Ringer plus $200 \mathrm{pg} / \mathrm{ml}$ of DA, its metabolites dihydroxyphenylacetic acid (DOPAC) and homovanillic acid (HVA) and the serotonin (5-HT) metabolite 5-hydroxyindoleacetic acid (5-HIAA) (plus $1 \mathrm{mg}$ ascorbate $/ 100 \mathrm{ml}$ ), which was maintained at $37^{\circ} \mathrm{C}$ in a water bath. After waiting $20 \mathrm{~min}$, two 10 -min dialysis samples were collected and the dialysate assayed by HPLC with electrochemical detection (HPLC-EC). Recovery was calculated for each probe as described previously ${ }^{31.51}$, and the average of two samples used.

\section{In vivo microdialysis procedures}

The inlet and outlet tubing were threaded through the lumen of a coiled steel tether, attached to a dental acrylic post on the animal's head, and attached to a liquid swivel (Harvard Bioscience). The dialysate was collected in minivials that were attached to the tether, about $35 \mathrm{~cm}$ above the animal. Thus, collection vials could be quickly exchanged without touching the animal or impeding its movement.

On the morning of a test day the pump speed was set at 1.5 $\mu \mathrm{l} / \mathrm{min}$, and after at least $30 \mathrm{~min}$, dialysate samples were collected. At least 5 baseline samples were collected over 20-50-min intervals. Samples were stored on ice for short periods, but all were assayed within $30 \mathrm{~min}$ of collection. After baseline samples were collected and assayed, the animals were placed onto the conveyor belt where they walked for $1 \mathrm{~h}$. During this time 3 more 20 -min samples were taken. At the end of the walking test, the animals were returned to the holding boxes and given a subcutaneous injection of $1.5 \mathrm{mg} / \mathrm{kg}$ of $D$-amphetamine sulfate (weight of the salt) in the neck. After this, 7 more samples were collected over 20 -min intervals.

Behavior was videotaped and subsequently analyzed by viewing the videotapes at 2 times normal speed. Behaviors scored were number of rears and the number of times the midline of the box was crossed.

\section{Assay of dialysate}

Dialysis samples were assayed by HPLC with series oxidativereductive electrochemical detection (HPLC-EC), and on a system used exclusively for dialysate. No more than $45 \mu \mathrm{l}$ of dialysate was injected directly on the column, with no pretreatment, via a Rheodyne injection valve with a $100-\mu$ l sample loop. The column was a $15 \mathrm{~cm}$ long Chromatography Sciences Company ODS-2 reverse-phase column $(\mathrm{C}-18 ; 5-\mu \mathrm{m}$ particles $0.46 \mathrm{~cm}$ i.d.). The mobile phase contained $0.06 \mathrm{M} \mathrm{NaPO}_{4}, 0.03 \mathrm{M}$ citric acid, $0.1 \mathrm{mM}$ EDTA, $20 \%$ methanol and $0.0936 \mathrm{mM}$ sodium dodecyl sulfate, at an apparent $\mathrm{pH}$ of 3.35. A Model 414 Kontron single piston HPLC pump was used to deliver dialysate samples to the column. The HPLC-EC system consisted of an ESA Model 5100A Coulochem Detector with a Model 5011 High Sensitivity Analytical Cell. A Model 5021 Conditioning Cell was positioned after the column but before the two analytical electrodes and was used to oxidize at +100 $\mathrm{mV}$. The first analytical electrode oxidized at $+340 \mathrm{mV}$ (gain 100 , filter setting 4) and was used to quantify DOPAC, HVA and 5-HIAA. The second analytical electrode reduced at $-230 \mathrm{mV}$ (gain 8500 . filter setting 10 ) and was used to quantify only DA. Under these conditions DA eluted relatively late, following DOPAC, 5-HIAA and HVA, and was usually separated from HVA by $2-3$ min. The total run time was $8-10 \mathrm{~min}$. Some sensitivity was lost because DA eluted so late, but because DA metabolite concentrations in dialysate are typically about 100 times greater than DA, it was found that the advantages of keeping DA well away from the metabolites outweighed the disadvantages.

Signals were recorded with a Linear 1200 dual pen recorder $(10$ $\mathrm{mV}$ full scale pen deflection), and the amount of each compound determined by comparison with the peak height of standards run with each assay $(4 \mathrm{pg} / \mu \mathrm{l}$ of DA and $200 \mathrm{pg} / \mu \mathrm{l}$ of DOPAC, HVA and 5-HIAA).

\section{Assay of brain tissue}

Tissue samples of anterior medial striatum, nucleus accumbens, and medial frontal neocortex were assayed for DA, DOPAC, HVA, norepinephrine (NE), 5-HT and 5-HIAA. At the end of the experiment the tubing leading to the dialysis probe was severed at the level of the dental cement 'cap', the open ends were sealed with epoxy, and the animal was returned to its home cage. At least 5 days later each animal was subsequently killed by decapitation and its brain rapidly removed and placed in ice-cold saline. After the brain cooled $(30-45 \mathrm{~s})$ it was placed in a chilled cutting block and brain slices obtained as described by Heffner et al. ${ }^{17}$. The slices were immediately examined and the approximate location of the 'track' formed by the dialysis probe was noted. The left and right striatum, nucleus accumbens, and medial frontal neocortex were then dissected out free-hand, weighed, and placed into individual tubes containing $0.05 \mathrm{~N}$ perchloric acid and dihydroxybenzylamine (internal standard). The samples were homogenized and centrifuged at $1500 \mathrm{~g}$ for $4 \mathrm{~min}$. The supernatant was assayed by HPLC-EC, using procedures similar to those described previously ${ }^{30}$.

\section{Data analysis}

Dialysate values are reported as fmol/min, after correcting for probe recovery. Baseline values represent $20-50$-min samples. The average $( \pm$ S.E.M.) relative recovery values for the probes used were: DA $25.30 \pm 1.00 \%$; DOPAC $25.41 \pm 0.79 \%$; HVA $23.99 \pm$ $0.79 \%$; and 5 -HIAA $27.45 \pm 1.07 \%$. Analyses of variance, $t$-tests, and correlation coefficients were performed using standard statistical packages

\section{RESULTS}

Activity measurements and tissue assays were obtained for all 20 rats, but, because of technical difficulties, incomplete dialysis results were obtained from 3 control rats and 2 DA-depleted rats. Thus, for the dialysis measures, results are reported for 15 rats. Furthermore, 5-HIAA was quantified in the dialysate of only 5 control rats and $5 \mathrm{DA}$-depleted rats.

\section{Post-mortem tissue measures and probe placement}

A summary of the average post-mortem tissue values for 6-OHDA-treated and control animals is given in Table I. There were no significant left/right asymmetries, so the values from the two sides were pooled for statistical comparisons. All of the 6-OHDA-treated rats had extensive bilateral striatal dopamine depletions (range $0.92-0.33 \%$ of the control mean). In addition, neocortical DA was reduced to $70 \%$, and nucleus accumbens DA to $8.1 \%$ of the control values. DOPAC concentrations were also significantly decreased in both 
TABLE I

Mean (ng/mg \pm S.E.M.) concentrations of the catecholamines, 5-HT and their metabolites in post-mortem tissue samples obtained from the medial frontal neocortex, striatum, and nucleus accumbens of neonatal 6-OHDA lesion $(n=10)$ and control $(n=10)$ groups

n.d., not detectable.

\begin{tabular}{|c|c|c|c|c|c|c|}
\hline & $D A$ & $D O P A C$ & $H V A$ & $N E$ & $5-H T$ & 5-HIAA \\
\hline \multicolumn{7}{|l|}{ Control } \\
\hline Cortex & $0.11(0.01)$ & $0.04(0.00)$ & n.d. & $0.45(0.02)$ & $0.91(0.07)$ & $0.31(0.02)$ \\
\hline Striatum & $14.88(0.42)$ & $1.36(0.04)$ & $0.78(0.04)$ & $0.10(0.005)$ & $0.82(0.05)$ & $0.48(0.02)$ \\
\hline Accumbens & $6.75(0.53)$ & $2.10(0.11)$ & $0.66(0.04)$ & $0.21(0.04)$ & $0.82(0.13)$ & $0.54(0.05)$ \\
\hline \multicolumn{7}{|l|}{ Lesion } \\
\hline Cortex & $0.08(0.01)^{*}$ & $0.04(0.01)$ & n.d. & $0.49(0.02)$ & $1.31(0.26)$ & $0.33(0.02)$ \\
\hline Percent & 69.7 & 93.3 & & 108.5 & 143.9 & 108.5 \\
\hline Striatum & $0.10(0.01)^{*}$ & $0.03(0.003)^{*}$ & n.d. & $0.07(0.01)^{*}$ & $2.50(0.28)^{*}$ & $0.96(0.06)^{*}$ \\
\hline Percent & 0.7 & 2.4 & & 68.2 & 306.9 & 201.2 \\
\hline Accumbens & $0.54(0.11)^{*}$ & $0.15(0.02)^{*}$ & n.d. & $0.39(0.12)$ & $1.11(0.14)$ & $0.68(0.05)^{*}$ \\
\hline Percent & 8.1 & 7.2 & & 182.7 & 136.1 & 125.7 \\
\hline
\end{tabular}

the striatum and nucleus accumbens, and HVA was below the detection limits of the assay in 6-OHDA treated rats (see Table I). Whereas NE was slightly, but not significantly, higher in the cortex and nucleus accumbens, it was reduced to $68 \%$ of control in the striatum $(t$-test, $P<0.05)$. In contrast to the catecholamines, 5-HT and 5-HIAA were elevated in all samples obtained from the 6-OHDA-treated group, and in the case of the striatal samples were $307 \%$ and $201 \%$ of the control values, respectively ( $t$-tests, $P<0.05$ ).

The dialysis probes were all located within the corpus of the neostriatum centered around the coronal plane located $0.8 \mathrm{~mm}$ anterior to bregma in the Paxinos and Watson ${ }^{28}$ atlas. Individual probes varied by $\pm 0.5 \mathrm{~mm}$ along the anterior-posterior axis. The dialysis tips ranged from 2 to $3 \mathrm{~mm}$ lateral to the midline in the mediallateral plane, and extended through the entire dorsalventral extent of the striatum (i.e. for about $4 \mathrm{~mm}$ ventral to the corpus callosum).

\section{General behavioral observations and noctural activity}

The neonatally depleted rats were able to sustain themselves on dry food and water, locomote seemingly normally, and orient to tactile stimuli such as touches from cotton-tipped probes inserted into their cages. They were impaired in eating efficiently, however, in that male rats were $35.5 \%$ lighter $\left(545.2\right.$ vs $351.4 \mathrm{~g}, t_{8}=5.49, P=$ 0.0006 ) and female rats were $28.5 \%$ lighter (308.6 vs $\left.220.6 \mathrm{~g}, t_{8}=3.35, P=0.01\right)$ than their respective control groups. They were also hyperactive when handled, tending to jump and squeal when lifted from their cage.

After being placed in the activity cages for measurement of overnight activity, the DA-depleted rats were initially more active than the control rats $(P<0.001$; Fig. 1). They also displayed high levels of activity relative to the control rats during the dark portion of the light-dark cycle $(P<0.001)$. Finally, during the light portion of the day-light cycle on the second day, the DA-depleted group was slightly, although significantly $(P<0.001)$, less active than the control rats.

\section{Behavior during dialysis}

All animals were habituated to the test chamber for 2 days prior to implantation of dialysis probes. They received further habituation by being left overnight in the test room, and during the next lights-on period. During this time the lights were on and background noise was provided by a radio tuned to a 'country and western' station. Therefore, they were generally inactive during baseline sample collection, sometimes falling asleep. The frequency of crossovers (locomotion) and rearing were calculated from the video record for a representative

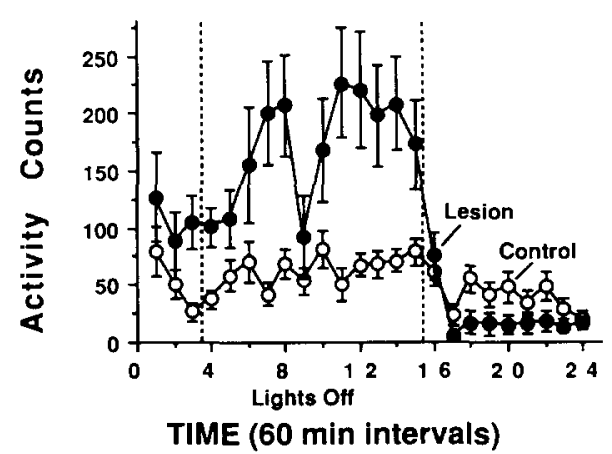

Fig. 1. Average ( \pm S.E.M.) activity counts (i.e. locomotion from one end of the cage to the other) in control and neonatally depleted rats during a 24-h test. Lights were off between 20.00 and $08.00 \mathrm{~h}$. Control, $n=10$; lesion, $n=10$. An overall analysis of variance resulted in a significant effect of group $\left(F_{1,18}=13.03, P=0.002\right)$, of time $\left(F_{23,414}=8.58, P<0.001\right)$ and a significant group by time interaction $\left(F_{23.414}=4.48, P<0.001\right)$. Subsequent Tukey tests confirmed significant group differences during the period of time prior to lights off, during the lights off period and after lights came back on. 
20 -min interval during the resting state (Fig. 2). There were no differences between the control and DAdepleted groups in numbers of crosses (control $=4.8 \pm$ 2.48 vs DA-depleted $=2 \pm 0.9, t_{17}=1.02, P=0.32$ ) or rears (control $=0.8 \pm 0.3$ vs DA-depleted $=1.6 \pm 0.7$. $t_{17}=1.09, P=0.29$ ).

Animals in both groups walked well when placed on the conveyor belt. Throughout the test, however, rats in the DA-depleted group were more energetic, staying away from the back wall of the container in which they walked. Rats in the control group frequently walked with their backs abutted to the rear wall of the restraining box, and they occasionally had to be pushed away from the wall.

In contrast, amphetamine produced a much greater increase in locomotion and rearing in the control animals than in the neonatally depleted animals (Fig. 2). In fact, amphetamine did not produce a significant change in crosses or rears in the DA-depleted animals.

\section{Extracellular DA and DA metabolites}

Fig. 3 illustrates the average extracellular concentrations of DA, DOPAC and HVA during rest, treadmill walking and after amphetamine, as estimated by the levels of these compounds in dialysate (i.e. dialysate values were corrected for probe recovery).
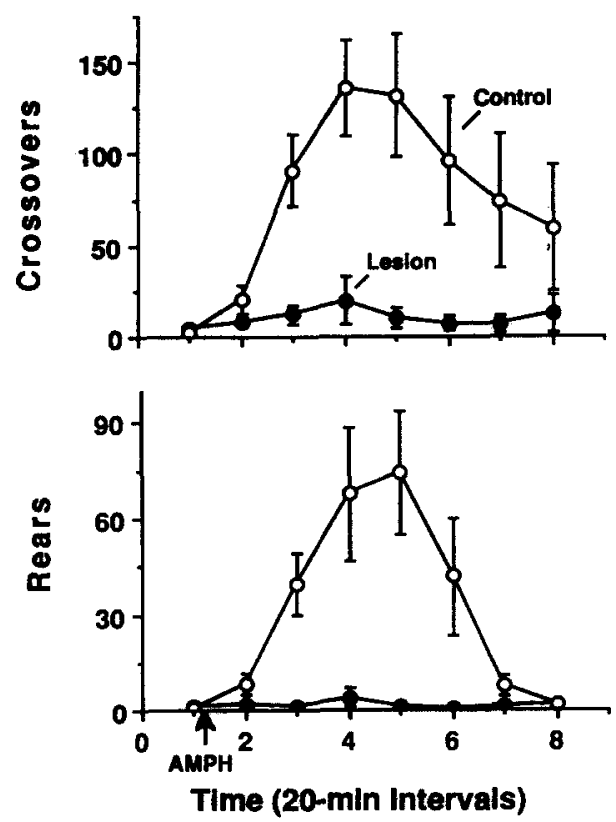

Fig. 2. Average ( \pm S.E.M.) number of crosses between two halves of the holding cage (top) and rears (bottom) during baseline (interval number 1) and after amphetamine (1.5 $\mathrm{mg} / \mathrm{kg}$ s.c.) treatment (intervals 2-8). Control, $n=7$, lesion, $n=8$. Analyses of variance showed that amphetamine produced a significant increase in both locomotion and rearing in control animals ( $F$ 's $=$ 6.06 and 5.99 , respectively, $P<0.001$ ), but had no effect on animals treated with 6-OHDA as neonates $(F$ 's $<1.0)$.
The extracellular concentrations of DA are illustrated in Fig. 3 (top), and an analysis of variance confirmed the impression that the control and neonatally depleted groups differed significantly across all 3 test conditions $(F$ $=35.7, P<0.001$; and follow-up Tukey tests). At rest. the average extracellular concentrations of DA in control animals was estimated to be $14.19 \mathrm{nM}$, and in neonatally depleted rats it was $4.77 \mathrm{nM}$, which is $33.6 \%$ of the control value. There was no significant change in extracellular DA during treadmill walking in either group, but $1.5 \mathrm{mg} / \mathrm{kg}$ of amphetamine produced a significant increase in extracellular DA in both groups. Fig. 4 (top) shows the extracellular concentrations of DA for just the neonatally depleted animals, with an expanded vertical scale, to better illustrate the effect of amphetamine administration in these animals. It is obvious, however, that the response of the neonatally depleted group was
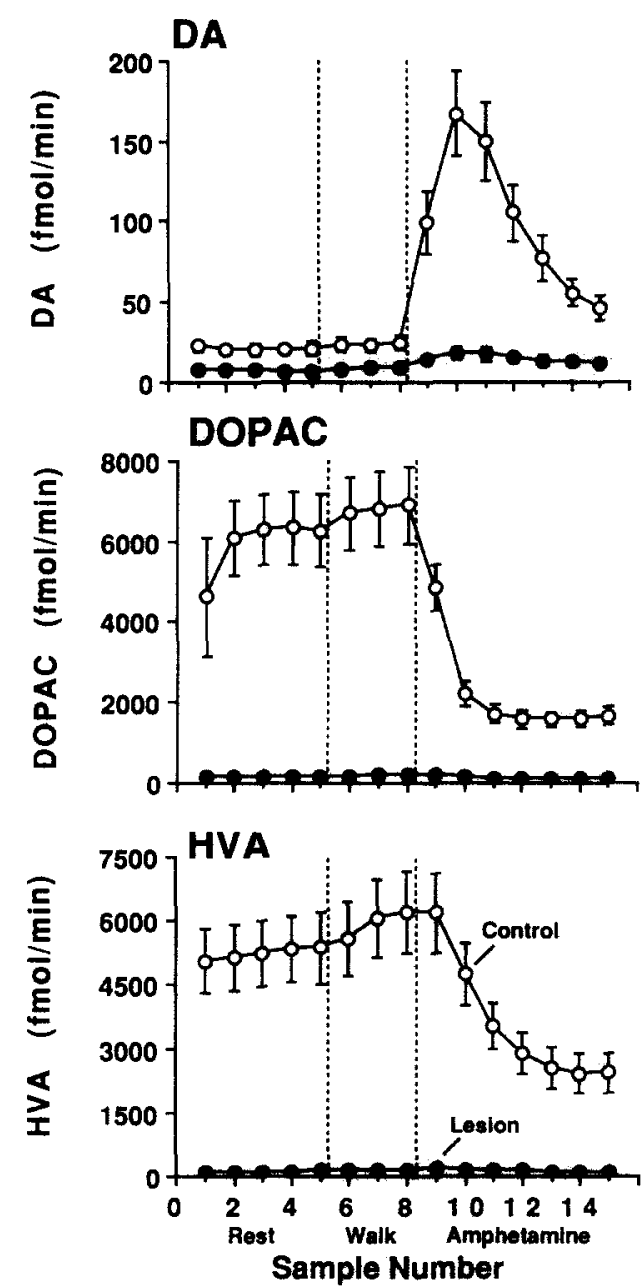

Fig. 3. Extracellular concentrations (mean \pm S.E.M.) of dopamine (DA, top), 3,4-dihydroxyphenylacetic acid (DOPAC, middle) and homovanillic acid (HVA, bottom) collected during 3 behavioral conditions: resting, walking in a treadmill and after $1.5 \mathrm{mg} / \mathrm{kg}$ amphetamine (s.c.) from control and neonatally dopamine-depleted rats. Each sample in each condition comprised 20 -min collection at $1.5 \mu \mathrm{l} / \mathrm{min}$. 
markedly deficient, relative to controls (Figs. 3 and 4).

The extracellular concentrations of the DA metabolites, DOPAC and HVA, are illustrated in Fig. 3 (middle and bottom panels). As with DA, the control and neonatally-depleted groups differed significantly across all 3 test conditions $(F$ 's $=53.3$ and $42.3, P<0.001$, DOPAC and HVA, respectively). At rest, the average extracellular concentrations of DOPAC and HVA in control animals were estimated to be 4212.41 and 3476.91 $\mathrm{nM}$, respectively; and in neonatally-depleted animals 96.20 and $70.80 \mathrm{nM}$, respectively. The extracellular concentrations of DOPAC and HVA in rats exposed to 6-OHDA as neonates were, therefore, $2.28 \%$ and $2.04 \%$ of the control values, respectively. There was no significant change in extracellular DOPAC or HVA in control animals during treadmill walking (Fig. 3), but both DA
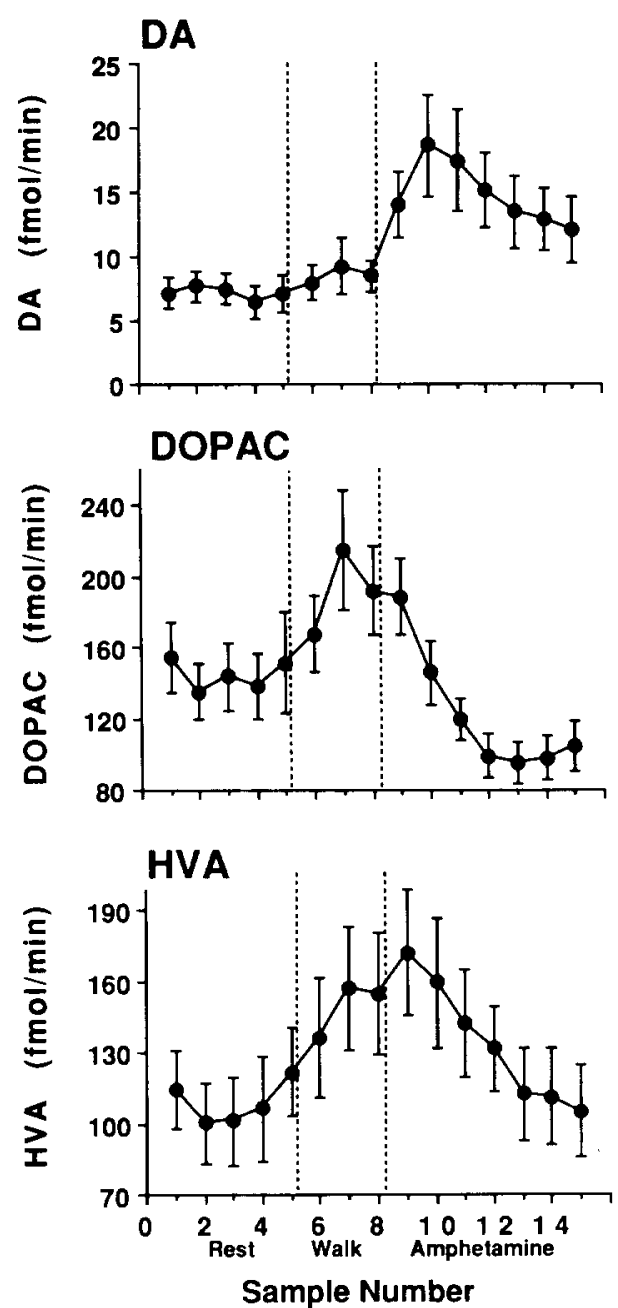

Fig. 4. Extracellular concentrations (mean \pm S.E.M.) of dopamine (DA, top), 3,4-dihydroxyphenylacetic acid (DOPAC, middle) and homovanillic acid (HVA, bottom) collected during 3 behavioral conditions: resting, walking in a treadmill and after $1.5 \mathrm{mg} / \mathrm{kg}$ amphetamine (s.c.) from neonatally dopamine-depleted rats. Each sample in each condition comprised 20 -min collection at $1.5 \mu \mathrm{l} / \mathrm{min}$. Note: the figure represents the data from the lesion group in Fig. 3 plotted against an expanded $y$-axis

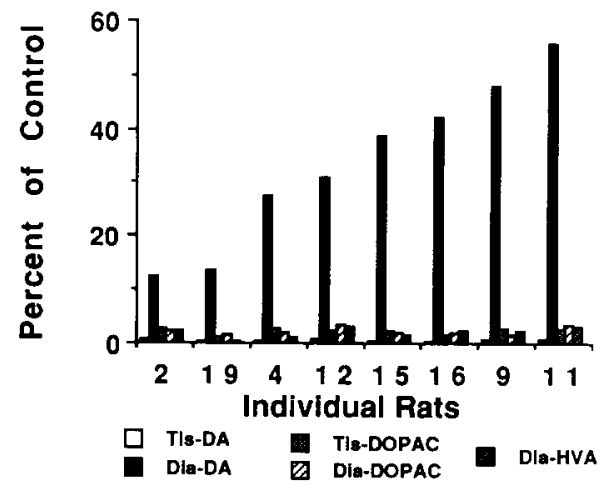

Fig. 5. Comparison of the tissue content of DA and its metabolites at post-mortem analysis and the dialysis content of these substances during resting conditions from 8 neonatal DA-depleted rats as a percent of control tissue and dialysis concentrations. Extracellular DA concentration (Dia-DA) was greater relative to tissue DA levels (Tis-DA: $\iota_{7}=5.99, P=0.0006$ ). In contrast, there was no significant difference between dialysate levels (Dia-DOPAC) and tissue content (Tis-DOPAC) of DOPAC $\left(t_{7}=0.089, P=0.93\right)$. Only dialysate levels for HVA (Dia-HVA) are shown because HVA was not detectable in the tissue assay.

metabolites levels rose significantly $(P<0.05$, Tukey test) during treadmill walking in the neonatally depleted group (Fig. 4); although this was a very small effect. Amphetamine treatment caused a significant decrease in extracellular DOPAC and HVA in both groups (Figs. 3 and 4)

Fig. 5 compares the post-mortem tissue levels of DA and its metabolites with the extracellular concentrations of these compounds in 8 individual neonatally depleted rats; with all values expressed as a percent of the respective control values. For DA, the post-mortem tissue concentrations were less than $1 \%$ of control in all animals (Fig. 5). In contrast, the extracellular concentrations of DA ranged from a low of $12 \%$ of control to a high of $56 \%$ of control. Thus, the extracellular concentrations of DA were much higher than would be predicted by the DA concentrations in post-mortem tissue. In contrast, there is a good relationship between

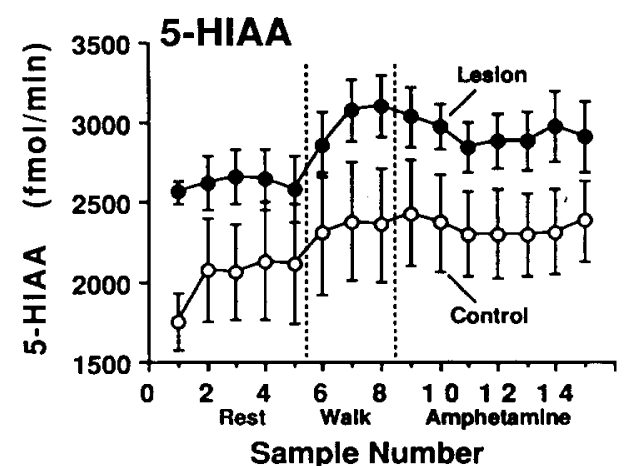

Fig. 6. Changes (mean \pm S.E.M.) in 5-hydroxyindoleacetic acid (5-HIAA) during 3 behaviors: resting, walking in a treadmill and after $1.5 \mathrm{mg} / \mathrm{kg}$ amphetamine (s.c.). Control, $n=5$; lesion, $n=5$. 
the post-mortem tissue concentrations of the DA metabolites and the concentrations of these compounds in extracellular fluid (Fig. 5).

The extracellular concentrations of 5-HIAA are illustrated in Fig. 6. As with the post-mortem tissue concentrations of 5-HT and 5-HIAA, neonatally depleted animals had higher extracellular levels of 5-HIAA than controls (although this difference did not reach statistical significance, perhaps because of the low $n, F_{1.8}=2.52$, $P=0.15$ ). The levels of 5-HIAA were slightly elevated in both groups during the walk and amphetamine conditions, relative to rest $(P<0.05)$.

\section{DISCUSSION}

The major finding in the present study is that the in vivo concentrations of DA in striatal extracellular fluid of adult freely behaving rats, which received DA-depleting lesions at 3 days of age, were substantially higher than would be predicted by DA concentrations in postmortem tissue. In rats that received 6-OHDA as neonates DA concentrations in post-mortem tissue were less than $1 \%$ of that in controls (range $0.92-0.33 \%$ of control). In striking contrast, the resting extracellular concentrations of DA, estimated from dialysate, ranged between 12 and $56 \%$ of control. These results suggest that some of the functional sparing seen after neonatal DA depletion could be due to the ability of the remaining DA terminals to maintain relatively high extracellular concentrations of DA.

The neuroplastic adaptations responsible for the apparent up-regulation of DA release seen following damage to DA neurons in neonates have not been well characterized, but studies in adults suggest a variety of changes probably interact to maintain extracellular DA levels ${ }^{47}$. For example, after partial damage the remaining DA cells greatly increase their rate of DA synthesis ${ }^{2}$. 3,19.20,56; first by an increase in the affinity of tyrosine hydroxylase for its cofactor, and later by an increase in the amount of tyrosine hydroxylase ${ }^{1.57}$. This enhanced synthetic capacity probably contributes to the ability of the remaining DA terminals to show large increases in fractional DA release in vitro ${ }^{43}$, which is consistent with the many reports of an increased ratio of DA metabolites to DA following partial DA depletion ${ }^{4,20,21,38}$. A 6OHDA lesion also destroys the DA re-uptake sites on DA terminals, leading to a reduction in DA re-uptake, and presumably a reduction in the rate that DA is removed from the extracellular fluid ${ }^{44.56}$. Thus, increased DA synthesis, increased DA release and decreased DA re-uptake probably all contribute to the relatively high extracellular concentrations of DA seen after partial DA depletion in adults ${ }^{31}$.
A question that remains to be answered, is whether the residual capacity of striatal DA neurons contribute significantly to the sparing of function seen after a neonatal 6-OHDA lesion. There are several lines of evidence which suggest residual dopaminergic activity is important. First, there is evidence showing that in adult animals given a partial 6-OHDA lesion presynaptic changes in the remaining DA terminals are crucial for recovery of function ${ }^{47.57}$. For example, inhibition of DA synthesis with $\alpha$-methyl- $p$-tyrosine reinstates feeding deficits in recovered rats with a 6-OHDA lesion ${ }^{58}$. Second, there is reason to believe that the extracellular concentrations of DA reported here should be sufficient to maintain some level of normal function. This is supported by studies in adults showing that lesions sparing even a small fraction $(\sim 5 \%)$ of the DA innervation to the striatum fail to produce pronounced behavioral deficits ${ }^{58}$. In addition, studies with intracerebral fetal substantia nigra or adrenal medulla grafts have shown that replacement of only a very small fraction of the normal complement of DA is sufficient to restore some function ${ }^{11,15}$.

The most convincing evidence, however, comes from a recent study on the effects of a second 6-OHDA lesion in adulthood on the behavior of rats previously given 6-OHDA as neonates ${ }^{32}$. Rogers and Dunnett ${ }^{32}$ report that of 21 rats given neonatal 6-OHDA, and then a second 6-OHDA lesion as adults, $16(76 \%)$ became severely aphagic and adipsic after the adult lesion, and 15 of these died within 13 days. Five of the 21 rats were able to maintain their body weight by 13 days after the adult lesion, but one of these had an incomplete lesion. Thus, a second 6-OHDA lesion given in adulthood to rats previously depleted of $\mathrm{DA}$ as neonates produced the adult syndrome of aphagia and adipsia, suggesting that in most of the animals residual dopaminergic activity was involved in the sparing of these functions subsequent to the neonatal lesion.

If residual DA neurons do contribute to the sparing of function seen after neonatal DA depletion, it is clear that at best they are able to provide only incomplete protection. Although rats given neonatal 6-OHDA are not aphagic, adipsic or akinetic they do show deficits in their ability to respond to a variety of regulatory challenges ${ }^{9,41}$. Furthermore, there are a number of sensory, motor and cognitive functions that are not appreciably spared following neonatal DA depletion. For example, deficits have been described in tests of spatial navigation ability, skilled forepaw use, limb posture ${ }^{53}$, spatial alternation ${ }^{13}$, rapid operant performance in a self-stimulation paradigm $^{45}$, and a variety of other sensorimotor and attentional functions ${ }^{3.3}$. It is particularly important to note that there is a significant positive correlation 
between the magnitude of the striatal depletion and the magnitude of the behavioral impairment seen in many of these tasks ${ }^{33,53}$. It is possible, therefore, that the inability of these animals to respond to various homeostatic challenges, or the demands of various test situations, could be related to their inability to further increase DA release in response to increased demand, as illustrated here by their failure to respond to an amphetamine challenge.

It must be emphasized here that there is also evidence to suggest that the sparing of function seen after neonatal DA depletion is not due to residual dopaminergic activity. Rats depleted of DA as neonates have been shown, in adulthood, to be insensitive to DA receptor antagonists. For example, a dose of haloperidol that significantly depresses motor activity in control animals has no effect on neonatally depleted rats tested as adults ${ }^{8}$. In addition, pimozide is less effective in depressing lateral hypothalamic self-stimulation in neonatally depleted rats than in controls ${ }^{45}$. This is in contrast to reports that recovered animals depleted of DA in adulthood are very sensitive to DA antagonists, which quickly reinstate deficits $^{18,58}$. A comparison of the effects of DA receptor antagonists in adult and neonatally depleted rats suggests that the mechanisms responsible for recovery of function in adults differ from those responsible for sparing of function in neonates.

Following neonatal DA depletion 5-HT levels are markedly elevated in the striatum ${ }^{22.42 .43}$, which has led to the suggestion that 5-HT neurons may be involved in sparing of function. Consistent with this hypothesis, we found that neonatally depleted rats showed increased extracellular concentrations of 5-HIAA and increased post-mortem tissue concentrations of 5-HT and 5-HIAA. However, more recent tests of this hypothesis have failed to support it ${ }^{6}$. For example, depletion of 5-HT does not prevent the sparing of function seen after neonatal 6-OHDA treatment. Furthermore, Whishaw et al. ${ }^{53}$ have reported that in neonatally depleted rats there is a negative, rather than a positive, correlation between post-mortem tissue concentrations of 5-HT and behavioral deficits in a variety of behavioral tasks. Therefore, it seems that the well documented increase in serotonin-

\section{REFERENCES}

1 Acheson, A.L. and Zigmond, M.J., Short and long term changes in tyrosine hydroxylase activity in rat brain after subtotal destruction of central noradrenergic neurons, $J$. Neurosci., 1 (1981) 493-504.

2 Agid, Y., Javoy, F. and Glowinski, J., Hyperactivity of remaining dopaminergic neurones after partial destruction of the nigro-striatal dopaminergic system in the rat, Nature, New Biol., 245 (1973) $150-151$.

3 Altar, C.A., Marien, M.R. and Marshall, J.F., Time course of ergic innervation of the striatum which occurs following early damage to dopaminergic systems is not responsible for sparing of function.

It is worth noting that we did not find a significant increase in DA release associated with conveyor belt walking, although DA metabolism was increased in the neonatally depleted group. Others have reported that dopaminergic activity is elevated in animals trained to walk in circles ${ }^{36.48 .55}$, or forward on a conveyor belt ${ }^{16}$. Freed and Yamamoto ${ }^{16}$ found that conveyor belt walking produced a much larger increase in DA metabolism in the nucleus accumbens than in the caudate, and in fact, the change in caudate DA content was only significant when animals walked at the fastest speeds they tested $(800 \mathrm{~cm} / \mathrm{min})$. In the present experiment animals walked at only $300 \mathrm{~cm} / \mathrm{min}$, which may explain the lack of effect on striatal DA release. Perhaps dialysis samples obtained from the nucleus accumbens would show more pronounced changes in association with speed of walking ${ }^{16}$.

In conclusion, it is not clear what kinds of neuroplastic adaptations are responsible for the sparing of function observed after damage to dopaminergic systems early in life. On one hand, residual DA neurons may be involved, as is the case in animals depleted of DA in adulthood. This idea is supported by the results reported here, which establish that the extracellular concentrations of DA in neonatally depleted rats are much higher than would be predicted by the extremely low concentrations of DA in post-mortem tissue; and, by the observation that a second 6-OHDA lesion in adulthood produces severe aphagia and adipsia in most animals ${ }^{32}$. On the other hand, residual DA activity may not be involved, as indicated by reports that animals depleted of DA as neonates are subsensitive to direct-acting DA receptor antagonists $^{8.45}$. Further studies will be required to distinguish between these two possibilities.

Acknowledgements. This research was conducted while E. Castañeda was an Albert Heritage Foundation for Medical Research Fellow. The research was supported by a grant from the Natural Sciences and Engineering Research Council of Canada for the HPLC equipment to I.Q.W. and from the Medical Research Council of Canada for operating expenses to I.Q.W. T.E.R. was supported by a Research Career Development Award from NINCDS and Grant 04294 from NIDA adaptions in dopamine biosynthesis, metabolism, and release following nigrostriatal lesions: implications for behavioral recovery from brain injury, $J$. Neurochem., 48 (1987) 390-399.

4 Bernheimer, H., Birkmayer, W., Hornykiewicz, O., Jellinger, $\mathrm{K}$. and Seitelberger, F., Brain dopamine and the syndromes of Parkinson and Huntington - clinical, morphological and neurochemical correlations, $J$. Neurol. Sci., 20 (1973) 415-455.

5 Breese, G.R., Baumeister, A.A., McCown. T.J., Emerick, G.D., Frye, G.D., Crotty, K. and Muller, R.A., Behavioral differences between neonatal and adult 6-hydroxydopaminetreated rats to dopamine agonists: relevance to neurological 
symptoms in clinical syndromes with reduced brain dopamine, $J$ Pharmacol. Exp. Ther., 231 (1984) 343-354.

6 Bruno, J.P., Jackson, D., Zigmond, M.J. and Stricker, E.M., Effect of dopamine-depleting brain lesions in rat pups: role of striatal serotonergic neurons in behavior, Behav. Neurosci., 101 (1987) 812-818.

7 Bruno, J.P., Snyder, A.M. and Stricker, E.M., Effect of dopamine-depleting brain lesions on suckling and weaning in rats, Behav. Neurosci., 98 (1984) 156-161.

8 Bruno, J.P., Stricker, E.M. and Zigmond, M.J., Rats given dopamine-depleting lesions as neonates are subsensitive to dopaminergic antagonists as adults, Behav. Neurosci., 99 (1985) $771-775$.

9 Bruno, J.P., Zigmond, M.J. and Stricker, E.M., Rats given dopamine-depleting lesions as neonates do not respond to acute homeostatic imbalances as adults, Behav. Neurosci, 100 (1986) 126-128.

10 Creese, I., Burt, D.R. and Snyder, S.H., Dopamine receptor binding enhancement accompanies lesion-induced behavioral sensitivity, Science, 197 (1977) 596-598.

11 Dunnett, S.B., Björklund, A., Gage, F.H. and Stenevi, U.. Transplantation of mesencephalic dopamine neurons to the striatum of adult rats. In A. Björklund and U. Stenevi (Eds.), Neural Grafting in the Mammalian CNS, Elsevier, Amsterdam, 1985, pp. 451-469.

12 Erinoff, L., MacPhail, R.C., Heller, A. and Seiden, L.S., Age-dependent effects of 6-hydroxydopamine on locomotor activity in the rat, Brain Research, 164 (1979) 195-205.

13 Feeser, H.R. and Raskin, L.A., Effects of neonatal dopamine depletion on spatial ability during ontogeny, Behav. Neurosci., 101 (1987) 812-818

14 Feltz, P. and De Clamplain, J., Enhanced sensitivity of caudate neurones to microiontophoretic injections of dopamine in 6-hydroxydopamine treated cats, Brain Research, 43 (1972) $601-605$.

15 Freed, W.J., Functional brain tissue transplantation: reversal of lesion induced rotation by intraventricular substantia nigra and adrenal medulla grafts, with a note on intracranial retinal grafts, Biol. Psychiatry, 18 (1983) 1205-1267.

16 Freed, C.R. and Yamamoto, B.K., Regional brain dopamine metabolism: a marker for the speed, direction, and posture of moving animals, Science, 229 (1985) 62-65.

17 Heffner, T.G., Hartman, J.A. and Seiden, L.S., A rapid method for the regional dissection of the rat brain, Pharmacol. Biochem. Behav., 13 (1980) 453-456.

18 Heffner, T.G., Zigmond, M.J. and Stricker, E.M., Effects of dopaminergic agonists and antagonists on feeding in intact and 6-hydroxydopamine rats, J. Pharmacol. Exp. Ther., 201 (1977) 386-399.

19 Hefti, F., Enz, A. and Melamed, E., Partial lesions of the nigrostriatal pathway in the rat-acceleration of transmitter synthesis and release of surviving dopaminergic neurones by drugs, Neuropharmacology, 24 (1985) 19-23

20 Hefti, F., Melamed, E. and Wurtman, R.J., Partial lesions of the dopaminergic nigrostriatal system in rat brain: biochemical characterization, Brain Research, 195 (1980) 123-137.

21 Hornykiewicz, O., Dopamine and extrapyramidal motor function and dysfunction. In Research Publications of the Association for Research in Nervous and Mental Disease, Vol. 50, Williams and Wilkins, Baltimore, 1972, pp. 390-415

22 Mailman, R.B., Towle, A., Schulz, D.A., Lewis, M.H., Breese, G.R., DeHaven, D.L. and Krigman, M.R., Neonatal 6-OHDA treatment of rats: changes in dopamine (LDA) receptors, striatal neurochemistry and anatomy, Soc. Neurosci. Abstr., 9 (1983) 932.

23 Marshall, J.F., Brain function: neural adaptations and recovery from injury, Annu. Rev. Psychol., 35 (1984) 277-308.

24 Marshall, J.F., Richardson, J.S. and Teitelbaum, P., Nigrostriatal bundle damage and the lateral hypothalamic syndrome, $J$. Comp. Physiol. Psychol. 87 (1974) 808-830.
25 Martin, J.P., The Basal Canglia and Posture, Pitman, London 1967.

26 Mishra, R.K., Gardner, E.L., Katzman, R. and Makman. M.H., Enhancement of dopamine-stimulated adenylate cyclase activity in rat caudate after lesions in the substantia nigra: evidence for denervation supersensitivity, Proc. Natl. Acad. Sci. U.S.A., 71 (1974) 3883-3887.

27 Neve, K.A., Kozlowski, M.R. and Marshall, J.F., Plasticity of neostriatal dopamine receptors after nigrostriatal injury: relationship to recovery of sensorimotor functions and behavioral supersensitivity, Brain Research, 244 (1982) 33-44

28 Paxinos, G. and Watson, C., The Rat Brain in Stereotaxic Coordinates, 2nd edn., Academic, New York, 1986.

29 Raskin, L.A., Schaywitz, B.A., Anderson, G.M., Cohen, D.J., Teicher, M.H. and Linakis, J., Differential effects of selective dopamine, norepinephrine or catecholamine depletions on activity and learning in the developing rat, Pharmacol. Biochem. and Behav., 19 (1983) 743-749.

30 Robinson, T.E., Becker, J.B., Young, E.A., Akil, H. and Castañeda, E., The effects of footshock stress on regional brain dopamine metabolism and pituitary $\beta$-endorphin release in rats previously sensitized to amphetamine, Neuropharmacology, 26 (1987) 679-691

31 Robinson, T.E. and Whishaw, I.Q., Normalization of extracellular dopamine in striatum following recovery from a partial unilateral 6-OHDA lesion of the substantia nigra: a microdialysis study in freely moving rats, Brain Research, 450 (1988) 209-224.

32 Rogers, D.C. and Dunnett, S.B., Neonatal dopamine-rich grafts and 6-OHDA lesions independently provide partial protection from the adult nigrostriatal lesion syndrome, Behav. Brain Res., 34 (1989) 131-146

33 Schallert, T., Petrie, B.F. and Whishaw, I.Q., Unspaired sensorimotor and attentional disorders following neonatal striatal dopamine depletion, Psychobiol., in press.

34 Schallert, T., Whishaw, I.Q., Ramirez, V.D and Teitelbaum, P., Compulsive, abnormal walking caused by anticholinergics in akinetic, 6-hydroxydopamine-treated rats, Science, 199 (1978) 1461-1463.

35 Schallert, T., Whishaw, I.Q., Ramirez, V.D. and Teitelbaum, P., The postures of catecholamine depletion catalepsy: their possible adaptive value in thermoregulation, Physiol. Behav., 21 (1978) 817-820.

36 Schwarting, R. and Huston, J,P., Dopamine and serotonin metabolism in brain sites ipsi- and contralateral to direction of conditioned turning in rats, $J$. Neurochem., 48 (1987) 1473-1479.

37 Schultz, W., Depletion of dopamine in the striatum as an experimental model of Parkinsonism: direct effects and adaptive mechanisms, Prog. Neurobiol., 18 (1982) 121-166.

38 Sharman, D.F., Poirier, L.J., Murphy, G.F. and Sourkes, T.L., Homovanillic acid and dihydroxyphenylacetic acid in the striatum of monkeys with brain lesions, Can. J. Physiol. Pharmacol., 45 (1967) 57-62.

39 Shaywitz, B.A., Klopper, J.H., Yager, R.D. and Gordon, J.W., Paradoxical response to amphetamine in developing rats treated with 6-hydroxydopamine, Nature (Lond.), 261 (1976) 153-155.

40 Shaywitz, B.A., Yager, R.D. and Klopper, J.H., Selective brain dopamine depletion in developing rats: an experimental model of minimal brain dysfunction, Science, 191 (1976) 305-308.

41 Smith, R.D., Cooper, B.R. and Breese, G.R., Growth and behavioral changes in developing rats treated intracisternally with 6-hydroxydopamine: evidence for involvement of brain dopamine, J. Pharmacol. Exp. Ther., 1985 (1973) 609-619.

42 Snyder, A.M., Zigmond, M.J. and Lund, R.D., Sprouting of serotoninergic afferents into striatum after dopamine-depleting lesions in infant rats: a retrograde transport and immunocytochemical study, J. Comp. Neurol., 245 (1986) 274-281.

43 Stachowiak, M.K., Bruno, J.P., Snyder, A.M., Stricker, E.M. and Zigmond, M.J., Apparent sprouting of striatal serotonergic terminals after dopamine-depleting lesions in neonatal rats, Brain Research, 291 (1984) 164-167. 
44 Stachowiak, M.K., Keller, R.W., Stricker, E.M. and Zigmond, M.J., Increased dopamine efflux from striatal slices during development and after nigrostriatal bundle damage, $J$. Neurosci., 7 (1987) 1648-1654.

45 Stellar, J.R., Waraczynski, M. and Bruno, J.P., Neonatal dopamine depletions spare lateral hypothalamic stimulation reward in adult rats, Pharmacol. Biochem. Behav., 30 (1988) $365-370$.

46 Stricker. E.M. and Zigmond. M.J., Effects on homeostasis of intraventricular injections of 6-hydroxydopamine in rats, $J$. Comp. Physiol. Psychol., 86 (1974) 973-994.

47 Stricker, E.M. and Zigmond, M.J., Recovery of function after damage to central catecholamine-containing neurons: a neurochemical model for the lateral hypothalamic syndrome. In J.M. Sprague and A.N. Epstein (Eds.). Progress in Psychobiology and Physiological Psychology. Vol. 6, Academic. New York, 1976, pp. 121-189.

48 Szostak, C., Jukubovic, A., Phillips, A.G. and Fibiger, H.C., Bilateral augmentation of dopaminergic and serotonergic activity in striatum and nucleus accumbens induced by conditioned circling, J. Neurosci, 6 (1986) 2037-2044.

49 Thornburg, J.E. and Moore, K.E., Supersensitivity to dopamine agonists following unilateral, 6-hydroxydopamine-induced striatal lesions in mice. J. Pharmacol. Exp. Ther., 192 (1975) $42-49$.

50 Ungerstedt. U., Adipsia and aphagia after 6-hydroxydopamine induced degeneration of the nigrostriatal dopamine system. Acta Physiol. Scand., 82 (1971) 96-122.

51 Ungerstedt, U., Measurement of neurotransmitter release by intracranial dialysis. In C.A. Marsden (Ed.), Measurement of Neurotransmitter Release In Vivo, Wiley, New York, 1984, pp.
$81-105$.

52 Whishaw, I.Q. and Dunnett, S.B., Dopamine depletion, stimulation or blockade in the rat disrupts spatial navigation and locomotion dependent upon beacon or distal cues, Behav. Brain Res., 18 (1985) 11-29.

53 Whishaw, I.Q., Funk, D.R., Hawryluk, S.J. and Karbashewski, E.D., Absence of sparing of spatial navigation, skilled forelimb and tongue use and limb posture in the rat after neonatal dopamine depletion, Physiol. Behav., 40 (1987) 247-253.

54 Whishaw, I.Q., Robinson, T.E., Schallert, T., DeRyck, M. and Ramirez, V.D.. Electrical activity of the hippocampus and neocortex in rats depleted of brain dopamine and norepinephrine: relations to behavior and effects of atropine, Exp. Neurol., 62 (1978) 748-767.

55 Yamamoto, B.K., Lane, R.F. and Freed, C.R., Normal rats trained to circle show asymmetric caudate dopamine release Life Sci., 30 (1982) 2155-2162.

56 Zigmond. M.J., Acheson, A.L., Stachowiak. M.K. and Stricker, E.M., Neurochemical compensation after nigrostriatal bundle injury in an animal model of preclinical parkinsonism, Arch. Neurol., 41 (1984) 856-861.

57 Zigmond. M.J., Stachowiak, M.K.. Berger. T.W. and Stricker E.M., Neurochemical events underlying continued function despite injury to monoaminergic systems, Exp. Brain Res. Suppl. 13 (1986) 119-128.

58 Zigmond, M.J. and Stricker, E.M., Recovery of feeding and drinking by rats after intraventricular 6-hydroxydopamine or lateral hypothalamic lesions, Science, 1982 (1973) 717-720.

$59 \mathrm{Zis}$, A.P., Fibiger, H.C. and Phillips, A.G.. Reversal by L-dopa of impaired learning due to destruction of the dopaminergic nigrostriatal projection, Science, 1985 (1974) 960-962

Note added in proof

The suggestion here that the relatively high extracellular concentrations of DA may be important for sparing of function in rats previously depleted of DA as neonates is supported in a recent paper by D.C. Rogers and S.B. Dunnett (Neurosci. Lett., 102 (1989) 108-113). These authors have shown that behavioral recovery of rats receiving neonatal 6-OHDA lesions is mediated by residual catecholamines because doses of $\alpha$-methyl- $p$-tyrosine that were ineffective in control animals disrupted feeding in neonatally depleted animals. 